\title{
AVALIAÇÃO DO IMPACTO DO FOGO NO ESTRATO DE REGENERAÇÃO EM UM TRECHO DE FLORESTA ESTACIONAL SEMIDECIDUAL EM VIÇOSA, MG ${ }^{1}$
}

\author{
Virgínia Londe de Camargos², Sebastião Venâncio Martins³, Guido Assunção Ribeiro³, Flávia Maria \\ da Silva Carmo ${ }^{4}$, Alexandre Francisco da Silva ${ }^{5}$
}

\begin{abstract}
RESUMO - Este estudo foi realizado em um fragmento de Floresta Estacional Semidecidual pertencente à Universidade Federal de Viçosa, Minas Gerais (20 $35^{\circ}-28^{\circ} 50^{\prime} \mathrm{S}$ e $\left.42^{\circ} 45^{\prime}-43^{\circ} 00^{\prime} \mathrm{W}\right)$, onde foram instaladas 10 parcelas de 5 x 5 m interdistantes $1 \mathrm{~m}$. Realizou-se a queima controlada nas parcelas utilizando a técnica do fogo a favor do vento e obedecendo ao sentido do aclive do terreno. Caracterizou-se florística e estruturalmente o estrato de regeneração natural antes e depois do fogo. O levantamento foi feito no canto superior direito de cada parcela, com o auxílio de um quadro de madeira de 1 x 1 m trançado com elástico em intervalos de $10 \mathrm{~cm}$, formando uma rede para mapeamento dos indivíduos amostrados em dois períodos distintos: antes do tratamento com o fogo e dois anos após. Foram amostradas nos dois inventários 24 espécies, pertencentes a 12 famílias. As famílias com maior riqueza específica foram: Rubiaceae (6), Fabaceae (4) e Myrtaceae (4). A similaridade florística foi de 35\%, sendo as espécies Sorocea bomplandii, Psychothria sessilis e Anadenanthera macrocarpa com maior valor de cobertura. Não houve redução significativa na densidade das espécies entre as amostragens, mas, sim, no índice de diversidade de Shannon. Os indivíduos amostrados eram de vegetação arbustiva e arbórea, sendo a rebrota mecanismo-chave na regeneração do fragmento.
\end{abstract}

Palavras-chave: Ecologia do fogo, Regeneração pós-fogo e Restauração ecológica.

\section{EVALUATION OF FIRE IMPACT IN THE REGENERATION STRATUM IN A SEASONAL SEMIDECIDUOUS FOREST SITE IN VIÇOSA, MG}

\begin{abstract}
This study was carried out in a fragment of a Seasonal Semideciduous Forest, which belongs to the Universidade Federal de Viçosa, Minas Gerais, Brazil $\left(20^{\circ} 35^{\prime}-28^{\circ} 50^{\prime} S\right.$ e $\left.42^{\circ} 45^{\prime}-43^{\circ} 00^{\prime} W\right)$, where ten $5 \times 5 \mathrm{~m}$ plots, $1 \mathrm{~m}$ away from each other, were set up. A controlled burning was performed on the plots, following the wind-driven fire technique, according to the slope orientation. The natural regeneration layer was floristically and structurally characterized before and after the fire. The floristic survey was performed on the upper right corner of each plot aided by a $1 \times 1 \mathrm{~m}$ wooden square strung with rubber bands each $10 \mathrm{~cm}$, making up a net for mapping the sampled individuals in two distinct periods; before fire treatment and then two years after that. Twenty four species and 12 families were sampled for both inventories. The families with greater species richness were: Rubiaceae (6), Fabaceae (4) e Myrtaceae (4). The floristic similarity found was 35\% and the species with higher cover value were: Sorocea bomplandii, Psychothria sessilis, and Anadenanthera macrocarpa. There was no meaningful reduction in the species density between the samplings, the same cannot be considered for the Shannon diversity index. The individuals sampled belonged to shrubby or woody vegetation, with resprouting being the key mechanism for this fragment regeneration.
\end{abstract}

Keywords: Fire ecology, Post-fire regeneration and Restoration ecology.

\footnotetext{
${ }^{1}$ Recebido em 01.07.2009 e aceito para publicação em 25.08.2010.

${ }^{2}$ Veracel Celulose, VERACEL, Brasil. E-mail: <virginialonde@yahoo.com.br>.

${ }^{3}$ Universidade Federal de Viçosa, Departamento de Engenharia Florestal, UFV, Brasil. E-mail: < venancio@ufv.br>e < gribeiro@ufv.br > .

${ }^{4}$ Universidade Federal de Viçosa, UFV, Brasil. E-mail: <fmcarmo@ufv.br >.

${ }^{5}$ In memorian.
} 


\section{INTRODUÇÃO}

Distúrbios naturais e antrópicos como atividade vulcânica, ataque de insetos, fogo e desmatamento alteram a dinâmica da vegetação florestal, iniciando um processo de sucessão secundária. A sucessão secundária logo após o fogo é extremamente importante porque as populações de espécies pioneiras definirão o progresso da regeneração em condições ecológicas gerais mais desfavoráveis e são importantes na determinação de estratégias de manejo e conservação de fragmentos florestais (CONNELL e SLATYER, 1977; UHL et al., 1981; BROWN et al., 1982; UHL, 1987; KAUFFMAN, 1991; COCHRANE e SCHULZE, 1999; MARTINS e RODRIGUES, 2002).

Após o fogo, os danos às árvores são os danos mais visíveis do fogo e que mais chamam atenção. Depois desse evento, a destruição total das árvores de grande porte não é muito freqüente, mas provoca morte de plântulas e árvores de pequeno diâmetro (WADE e LUNDSORD, 1990). Além disso, afeta diretamente o crescimento, sobrevivência e reprodução das plantas, além de causar impactos no banco de sementes (HOFFMANN, 1996). No entanto, a resposta das plantas a esse impacto varia conforme o regime do fogo, caracterizado pela freqüência, época de ocorrência (estação do ano) e duração dos incêndios, e também o estágio de sucessão e a formação vegetacional atingida. Em certas formações, várias espécies resistem à ocorrência do fogo ou são até mesmo favorecidas por ele, uma vez que as altas temperaturas ajudam a quebrar a dormência de algumas espécies (COUTINHO, 1978, 1990; COCHRANE e SCHULZE, 1999; GERWING, 2002).

Em Minas Gerais, o bioma Floresta Atlântica compreende diferentes formações florestais, sendo, em grande parte, ocupada por Florestas Estacionais Semideciduais, que recobrem praticamente todo o Leste mineiro. Várias espécies do bioma encontram-se na "Lista de Espécies Ameaçadas de Extinção da Flora do Estado de Minas Gerais” (COSTA et al., 1998). Essa tipologia florestal não apresenta características de adaptação a ocorrências de fogo. A grande exploração agrícola na região tem resultado em aumento da devastação por fogo, transformado essas paisagens em mosaicos de campos de cultura e florestas secundárias (BONFIM et al., 2003)
Em Floresta Estacional Semidecidual ainda são poucos os estudos sobre o impacto do fogo na capacidade de regeneração (CASTELLANI e STUBBLEBINE, 1993; MARTINS e RIBEIRO, 2002; MARTINS et al., 2002; SILVA et al., 2005; RODRIGUES et al., 2005), e os resultados têm mostrado complexa resposta da vegetação a distúrbios tanto na dinâmica sucessional quanto na composição e densidade de espécies, indicando potencial de regeneração muito variável, que depende do tamanho, tempo de ocorrência, frequência e características ecológicas da vegetação (CLARK e CLARCK, 1987).

Os objetivos deste estudo foram caracterizar florística e estruturalmente o estrato de regeneração natural em um trecho de Floresta Estacional Semidecídua antes e depois do tratamento com fogo e verificar sua conseqüência na estrutura da comunidade, bem como na diversidade de espécies, visando fornecer informações sobre a restauração florestal em fragmentos degradados por incêndios.

\section{MATERIAL E MÉTODOS}

O estudo foi realizado em um fragmento de Floresta Estacional Semidecidual Montana (VELOSO et al., 1991) em regeneração natural há 80 anos, conhecido como "Reserva da Biologia”, situado no campus da Universidade Federal de Viçosa, no Município de Viçosa, MG (20³5'-28 $8^{\circ} 50^{\prime}$ 'S e $\left.42^{\circ} 45^{\prime}-43^{\circ} 00^{\prime} \mathrm{W}\right)$. A área total do fragmento é de 75 ha, com altitude variando entre 725 e 745 m. O relevo possuí características montanhosas, com predominância de solos tipo Latossolo Vermelho-Amarelo Álico nos topos e encostas e Podzólico Vermelho-Amarelo Câmbico nos terraços (CORREA, 1984). O clima, segundo a classificação de Köppen, é do tipo $\mathrm{Cw}_{\mathrm{b}}$, subtropical moderado úmido, com verões chuvosos e invernos secos. A precipitação anual está em entorno de 1.314,2 mm (CASTRO et al., 1983).

Em um trecho de encosta da Reserva com face de exposição solar oeste-sudeste foram instaladas 10 parcelas de 5 x $5 \mathrm{~m}$, dispostas em linha vertical e interdistantes em $1 \mathrm{~m}$, formando uma faixa vertical, num total de $250 \mathrm{~m}^{2}$. Entre as parcelas e em seu contorno, foram construídos aceiros de $1 \mathrm{~m}$ de largura para conter o avanço do fogo. Cada parcela foi submetida à queima controlada utilizando a técnica do fogo a favor do vento. Obedecendo ao sentido do aclive, a linha de fogo foi acesa na parcela situada no extremo oposto ao topo do morro, com o auxílio de um “pinga-fogo”. A queima 
foi realizada dia 5 de setembro de 2005, após um período de 30 dias sem chuva. O ano de 2005 foi atípico, pois somente nos cinco primeiros dias do mês de agosto foi registrada precipitação de $62 \mathrm{~mm}$, que no mesmo período, em 2004 e 2006, foi de 0,2 e 13,3 mm. Aqueima foi iniciada às 9 h30 e teve duração total de 2 h entre a ignição e a extinção total, com tempo médio de queima de 6min20s por parcela, temperatura de $20^{\circ} \mathrm{C}$, umidade relativa de $79 \%$, velocidade média do vento de $3,5 \mathrm{~m} / \mathrm{s}^{-1}$ e velocidade média de propagação do fogo de $0,017 \mathrm{~m} / \mathrm{s}^{-1}$.

A caracterização do estrato da regeneração foi realizada em dois períodos distintos, antes do tratamento com o fogo e dois anos após, sendo o levantamento realizado no canto superior direito de cada parcela. Utilizou-se um quadro de madeira de 1 x $1 \mathrm{~m}$, trançado com elástico em intervalos de $10 \mathrm{~cm}$ (Figura 1), formando uma rede para mapeamento dos indivíduos. Todas as plantas com diâmetro à altura do solo (DAS) igual ou inferior a $5 \mathrm{~cm}$ foram marcadas e numeradas de acordo com a localização nesse quadro e identificadas. Para a classificação taxonômica, foi adotado Angiosperm Phylogeny Group II (APG II, 2003).

Avaliou-se o mecanismo de estabelecimento dos indivíduos com pequenas escavações, quando necessário, para determinar se a regeneração após o tratamento havia sido por rebrota ou germinação de sementes.

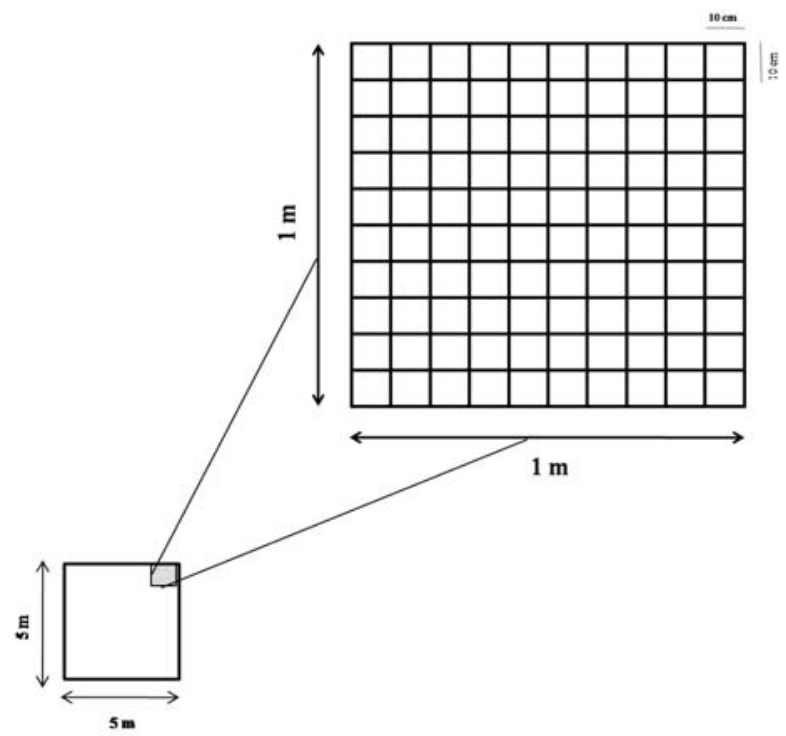

Figura 1 - Desenho esquemático das parcelas de amostragem da regeneração.

Figure 1 - Schematical drawing of the plots of regeneration sampling.
As espécies identificadas foram classificadas quanto ao grupo ecológico em pioneiras, secundárias iniciais e tardias (PAULA et al., 2002; MARTINS e RODRIGUES, 2002; GANDOLFI, 2000), visando correlacionar a resposta das plantas por grupo ecológico após o fogo.

Para as duas etapas, antes e após o fogo, determinou-se o número de indivíduos total e por espécie, bem como foram calculados o índice de diversidade de Shannon (H') e a equabilidade (J') (PIELOU, 1975). Para avaliar se entre as duas etapas existia diferença significativa na diversidade, realizou-se a comparação entre os valores de H', através do teste t de Magurran (1989). Entre as espécies comuns foi realizada uma análise de variância simples, considerando o número de indivíduos nas duas amostragens.

Para comparar floristicamente as duas etapas, antes e depois do fogo, realizou-se uma análise de agrupamento pelo método média de grupo (UPGMA), com base nos índices de similaridade de Jaccard (PIELOU, 1975), calculados a partir de uma matriz de presença e ausência das espécies amostradas nas 10 parcelas e nas duas amostragens.

Foram determinados para as amostras antes e depois do fogo os parâmetros densidade relativa (DR), valor de cobertura $(\mathrm{VC}=\mathrm{DR}+\mathrm{DoR} / 2)$ e frequência relativa (FR) (MUELLER-DOMBOIS e ELLENBERG, 1974), utilizando o Programa Mata Nativa (CIENTEC, 2006).

\section{RESULTADOS}

O material combustível coletado para avaliar os parâmetros do comportamento do fogo era composto de folhas verdes e secas, ramos e galhos mortos e algumas gramíneas. A umidade desse material no dia da queima estava em $17,17 \%$, o qual foi parcialmente consumido durante a passagem do fogo. A altura das chamas não foi medida, por ser o fogo bastante rasteiro. A intensidade variou de 11,94 a $75,79 \mathrm{kcal} . \mathrm{s}^{-1} \cdot \mathrm{m}^{-1}$ entre as parcelas e foi classificada em muito baixa ( 0 a $80 \mathrm{kcal} . \mathrm{s}^{-1} \cdot \mathrm{m}^{-1}$ ), de acordo com a escala de Mcarthur e Cheney (1966).

Foram registrados no inventário antes do fogo, em 2005, 78 indivíduos vivos, distribuídos em 22 espécies e 11 famílias. Após o fogo, em 2007 foram 76 indivíduos, em 14 espécies e oito famílias. A perda de densidade entre um inventário e outro foi de apenas 2,5\%, não sendo significativo estatisticamente $(\mathrm{P}>0,05)$ (Tabela 1$)$.

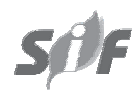

Revista Árvore, Viçosa-MG, v.34, n.6, p.1055 -1063, 2010 
Tabela 1 - Número de indivíduos (N), densidade relativa (DR), frequência relativa (FR) e valor de cobertura (VC) das espécies amostradas antes e depois do tratamento com fogo, em um trecho de Floresta Estacional Semidecidual, Viçosa, MG.

Table 1 - Number of individuals $(N)$, relative density (DR), relative frequency (FR), and cover value (VC) of the sampled species before and after the fire in a semideciduous forest site, Viçosa, MG.

\begin{tabular}{|c|c|c|c|c|c|c|c|c|}
\hline \multirow[t]{2}{*}{ Espécies } & \multicolumn{4}{|c|}{ Antes do fogo } & \multicolumn{4}{|c|}{ Após o fogo } \\
\hline & $\mathrm{N}$ & DR(\%) & $\mathrm{FR}(\%)$ & $\mathrm{VC}(\%)$ & $\mathrm{N}$ & DR(\%) & FR(\%) & $\mathrm{VC}(\%)$ \\
\hline Sorocea bomplandii & 15 & 19,23 & 70 & 16,19 & 21 & 27,63 & 70 & 17,85 \\
\hline Psychotria sessilis & 15 & 19,23 & 40 & 16,84 & 9 & 11,84 & 30 & 27,97 \\
\hline Protium warmingiana & 4 & 5,13 & 30 & 11,05 & 1 & 3,95 & 10 & 3,5 \\
\hline Croton urucurana & 7 & 8,97 & 40 & 6,54 & 7 & 9,21 & 30 & 5,55 \\
\hline Anadenanthera macrocarpha & 6 & 7,69 & 30 & 7,66 & 9 & 11,84 & 50 & 8,99 \\
\hline Astronium fraxinifolium & 4 & 5,13 & 20 & 4,87 & - & - & - & - \\
\hline Mollinedea argyrogyna & 3 & 3,85 & 20 & 4,31 & - & - & - & - \\
\hline Coutarea hexandra & 2 & 2,56 & 20 & 4,06 & - & - & - & - \\
\hline Inga edulis & 1 & 1,28 & 10 & 4,29 & 1 & 1,32 & 10 & 8,77 \\
\hline Endlicheria paniculata & 1 & 1,28 & 10 & 4,07 & - & - & - & - \\
\hline Plinia glomerata & 4 & 5,13 & 20 & 2,91 & 4 & 5,26 & 20 & 2,84 \\
\hline Psichotria carthagenensis & 2 & 2,56 & 20 & 2,85 & - & - & - & - \\
\hline Psychotria hasticephala & 3 & 3,85 & 20 & 2,35 & 3 & 3,95 & 10 & 3,5 \\
\hline Amaioua guianensis & 1 & 1,28 & 10 & 2,4 & 1 & 1,32 & 10 & 5,64 \\
\hline Eugenia uniflora & 3 & 3,85 & 10 & 2,08 & - & - & - & - \\
\hline Dalbergia nigra & 1 & 1,28 & 10 & 1,8 & 4 & 5,26 & 40 & 4,02 \\
\hline Rudgea myrsinifolia & 1 & 1,28 & 10 & 1,68 & - & - & - & - \\
\hline Vernonanthura divaricata & 1 & 1,28 & 10 & 1,02 & - & - & - & - \\
\hline Lacistema pubescens & 1 & 1,28 & 10 & 0,85 & - & - & - & - \\
\hline Myrcia fallax & 1 & 1,28 & 10 & 0,78 & 1 & 1,32 & 10 & 1,11 \\
\hline Myrciaria ciliolata & 1 & 1,28 & 10 & 0,75 & 1 & 1,32 & 10 & 0,89 \\
\hline Apuleia leiocarpa & 1 & 1,28 & 10 & 0,64 & - & - & - & - \\
\hline Acanthinophyllum ilicifolia & - & - & - & - & 13 & 17,11 & 60 & 11,14 \\
\hline Siparuna guianensis & - & - & - & - & 1 & 1,32 & 10 & 0,79 \\
\hline Total & 78 & 100 & 100 & 100 & 76 & 100 & 100 & 100 \\
\hline
\end{tabular}

Uma questão crítica para o entendimento do efeito do fogo na composição da floresta se refere à sua atuação na seletividade de espécies resistentes a ele. Neste estudo, a redução no número de espécies de um inventário para o outro foi de $45 \%$, sendo elas representadas por poucos indivíduos no fragmento.

O total de identificações nas duas amostragens foi de 24 espécies e 12 famílias (Tabela 2). A família Rubiaceae destacou-se pela maior riqueza antes do fogo, com seis espécies, representando $27 \%$ do inventário; em seguida, Fabaceae (Leguminosae) e Myrtaceae, com quatro espécies cada. Após o fogo, essas três famílias também foram as mais representativas em riqueza, porém com apenas três espécie cada, seguidas de Moraceae, com duas. As outras oito famílias, com apenas uma espécie cada, antes e depois do fogo, representaram 33\% do total.

O dois inventários diferiram quanto à diversidade de espécies, apresentando índices de diversidade de Shannon para antes do fogo $\left(H^{\prime}=2,63\right)$ significativamente superior ao encontrado depois do fogo $\left(H^{\prime}=2,16\right)(\mathrm{t}=3,48 ; \mathrm{P}<0,01)$.
O índice de Jaccard ( $\mathrm{J}$ ) foi de 35\%, indicando alta similaridade de espécies entre as duas amostragens, uma vez que, segundo Mueller-Dombois e Ellenberg (1974), quando o valor desse índice é superior a 25\%, as duas amostras comparadas são consideradas floristicamente semelhantes.

O dendrograma de similaridade (Figura 2) entre as parcelas dos inventários realizados antes e depois do fogo mostra seis grupos similares e três grandes grupos com maior diferença na composição de espécies entre elas, demonstrando que existe heterogeneidade espacial florística. As parcelas 2 e 4 agruparam-se antes e depois do fogo, com similaridade de 65 e 58\%, respectivamente.

A rebrota foi a estratégia de sucesso nas parcelas 2(AF e PF) e 4(AF e PF), ocorrendo em mais de $60 \%$ dos indivíduos amostrados. A parcela 7PF ficou isolada do restante, apresentando similaridade muito baixa em relação às demais, ou seja: 4\%. Das 14 espécies estabelecidas na área após o fogo, 11 apresentaram 
Tabela 2 - Espécies amostradas antes (AF) e depois (PF) do tratamento com fogo, em um trecho de Floresta Estacional Semidecídua, Viçosa, MG

Table 2 - Sampled species before (AF) and after (PF) fire in a seasonal semideciduous forest site in Viçosa, MG.

\begin{tabular}{|c|c|c|c|c|}
\hline Família/Espécie & GE & $\mathrm{AF}$ & $\mathrm{PF}$ & $\mathrm{RB}$ \\
\hline \multicolumn{5}{|l|}{$\overline{\text { ANACARDIACEAE }}$} \\
\hline $\begin{array}{l}\text { Astronium fraxinifolium Schott ex Spreng. } \\
\text { ASTERACEAE }\end{array}$ & ST & $\mathrm{X}$ & & \\
\hline \multicolumn{4}{|l|}{ BURSERACEAE } & \\
\hline $\begin{array}{l}\text { Protium warmingiana March,L. } \\
\text { EUPHORBIACEAE }\end{array}$ & ST & $\mathrm{X}$ & $\mathrm{X}$ & $\mathrm{X}$ \\
\hline $\begin{array}{l}\text { Croton urucurana Baill. } \\
\text { FABACEAE }\end{array}$ & \multicolumn{3}{|c|}{ FABACEAE } & $\mathrm{X}$ \\
\hline Anadenanthera macrocarpa (Benth.) Brenan & SI & $\mathrm{X}$ & $\mathrm{X}$ & $\mathrm{X}$ \\
\hline Apuleia leiocarpa (Vogel) J.F. Macbr. & SI & $\mathrm{X}$ & & \\
\hline Dalbergia nigra (Vell.) Allemao ex Benth. & SI & $\mathrm{X}$ & $\mathrm{X}$ & \\
\hline Inga edulis Mart. & SI & $\mathrm{X}$ & $\mathrm{X}$ & $\mathrm{X}$ \\
\hline \multicolumn{5}{|l|}{ LACISTEMATACEAE } \\
\hline $\begin{array}{l}\text { Lacistema pubescens Mart. } \\
\text { LAURACEAE }\end{array}$ & SI & $\mathrm{X}$ & & \\
\hline $\begin{array}{l}\text { Endlicheria paniculata (Spreng.) J.F. Macbr. } \\
\text { MONIMIACEAE }\end{array}$ & $\mathrm{ST}$ & $\mathrm{X}$ & & \\
\hline \multicolumn{3}{|l|}{ MORACEAE } & & \\
\hline Acanthinophyllum ilicifolia (Spreng.) W.C. Burger & SI & & $\mathrm{X}$ & \\
\hline $\begin{array}{l}\text { Sorocea bonplandii (Baill.) W.C. Burger, Lanj. } \\
\text { \& Wess. Boer }\end{array}$ & SI & $\mathrm{X}$ & $\mathrm{X}$ & $\mathrm{X}$ \\
\hline \multicolumn{5}{|l|}{ MYRTACEAE } \\
\hline Eugenia uniflora L. & $\mathrm{ST}$ & $\mathrm{X}$ & & \\
\hline Plinia glomerata (O. Berg) Amshoff & SI & $\mathrm{X}$ & $\mathrm{X}$ & $\mathrm{X}$ \\
\hline Myrcia fallax (Rich.) DC. & SI & $\mathrm{X}$ & $\mathrm{X}$ & $\mathrm{X}$ \\
\hline \multicolumn{4}{|l|}{ RUBIACEAE } & $\mathrm{X}$ \\
\hline Amaioua guianensis Aubl. & SI & $\mathrm{X}$ & $\mathrm{X}$ & $\mathrm{X}$ \\
\hline Coutarea hexandra(Jacq.) K. Shum. & SI & $\mathrm{X}$ & & \\
\hline Psychotria carthagenensis Jacq. & SI & $\mathrm{X}$ & & \\
\hline Psychotria hastisepala Müll. Arg. & SI & $\mathrm{X}$ & $\mathrm{X}$ & $\mathrm{X}$ \\
\hline Psychotria sessilis (Vell.) Müll. Arg. & SI & $\mathrm{X}$ & $\mathrm{X}$ & $\mathrm{X}$ \\
\hline Rudgea myrsinifolia Benth. & SI & $\mathrm{X}$ & & \\
\hline \multicolumn{5}{|l|}{ SIPARUNACEAE } \\
\hline Siparuna guianensis Aubl. & SI & & $\mathrm{X}$ & \\
\hline
\end{tabular}

rebrota pelo caule e, ou, estrutura subterrânea (Tabela 1), representando $79 \%$ das espécies e $76 \%$ dos indivíduos encontrados depois do fogo.

As espécies secundárias iniciais foram as mais relevantes nos dois inventários, totalizando 77 e 86\% antes e depois do fogo, respectivamente. No inventário antes e depois do fogo somente Croton urucurana foi classificada como pioneira, enquanto Astronium fraxinifolium, Endlicheria paniculata e Eugenia uniflora o foram como secundárias tardias e ocorreram somente no levantamento antes do fogo. Já Protium warmingiana, considerada secundária tardia, ocorreu nos dois inventários.

Constatou-se nesse trecho do fragmento que o estrato herbáceo-arbustivo não era denso, apresentando muitos indivíduos jovens do estrato arbóreo e algumas espécies do gênero Justicia (Acanthacaea), Piper e Ottonia (Piperaceae) e Psychotria (Rubiaceae). Apesar de nenhuma forma de vida ter sido excluída, não foi registrada ocorrência de espécies herbáceas antes e depois do fogo.

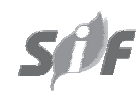

Revista Árvore, Viçosa-MG, v.34, n.6, p.1055 -1063, 2010 


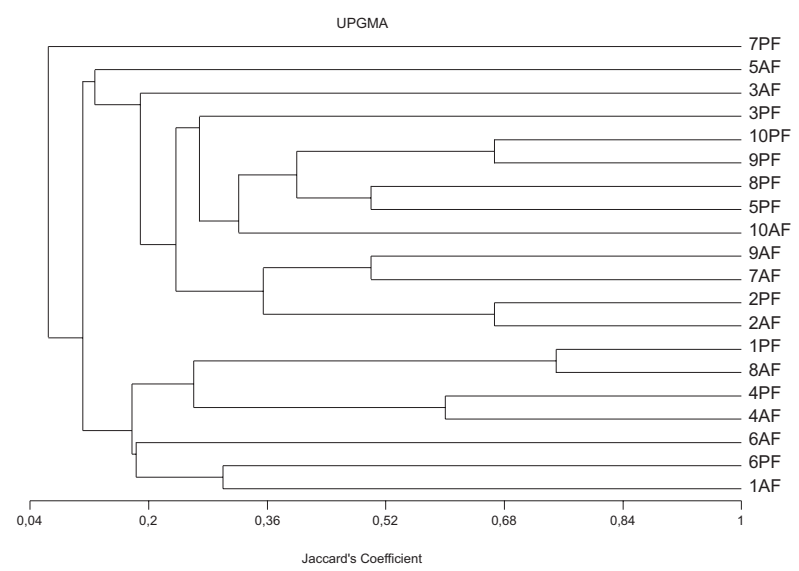

Figura 2 - Dendrograma obtido pelo método média de grupo (UPGMA), com base no índice de Jaccard. Floresta Estacional Semidecidual, Viçosa, MG. Parcelas 1 a $10 \mathrm{AF}=$ antes do fogo; parcelas 1 a $10 \mathrm{PF}=$ após o fogo.

Figure 2 - Dendrogram obtined using the Jaccard similarity index and average linkage method (UPGMA). Seasonal Semideciduous Forest Site, Viçosa, MG, Brazil. Plots 1 to $10 \mathrm{AF}=$ before the fire; Plots 1 to $10 \mathrm{PF}=$ after the fire.

Os dados da estrutura da vegetação são apresentados na Tabela 1. Das 24 espécies encontradas, 12 tiveram diminuição no número de indivíduos e sete não sofreram alteração após a queima. Observa-se, nessa tabela, que a comunidade exibiu forte dominância de algumas espécies. Os maiores valores de cobertura (VC) e de densidade relativa (DR) nos dois inventários foram apresentados por Sorocea bomplandii, Psychothria sessilis e Anadenanthera macrocarpa.

Quanto à frequência relativa (FR), somente uma espécie, Sorocea bomplandii, ocorreu em mais de 50\% das parcelas estando presente em sete parcelas antes do fogo; e duas em mais de $50 \%$ após o fogo, Sorocea bomplandii em sete parcelas e Acanthinophyllum ilicifolia em seis.

P. sessilis apresentou maior VC nas amostragens, sendo $16,84 \%$ antes e $27,97 \%$ depois do fogo, mesmo tendo reduzido o número de indivíduos após o incêndio. Vale ressaltar que essa espécie foi a que apresentou maior rebrota pelo caule, ramificando-se após o fogo.

Acanthinophyllum ilicifolia e Siparuna guianensis ocorreram somente no inventário após o fogo.
Astronium fraxinifolium, Mollinedea argyrogyna e Coutarea hexandra foram bastante representativas no primeiro inventário, apresentando considerável VC. Após o fogo, foram eliminadas completamente, mostrando suscetibilidade ao tratamento.

\section{DISCUSSÃO}

O destaque das famílias Rubiaceae e Myrtaceae no estrato de regeneração tanto antes quanto após o tratamento com fogo corrobora com Tabarelli et al. (1994), que consideram essas famílias importantes desde os estágios iniciais da sucessão dentro do domínio da Floresta Atlântica, no desenvolvimento da comunidade, principalmente do sub-bosque.

A diferença encontrada no índice de diversidade de Shannon antes $\left(\mathrm{H}^{\prime}=2,63\right)$ e depois do fogo $\left(H^{\prime}=2,16\right)$ mostrou que houve redução significativa da diversidade entre os dois inventários - antes e depois do fogo, apesar de não ter havido a mesma situação para a densidade total de indivíduos. Contrariando esse resultado, um estudo sobre o efeito do fogo em componente arbóreo em Floresta Estacional Semidecidual revelou redução de $42 \%$ na densidade de árvores vivas após o fogo, mas aumento na diversidade de espécies (SILVA et al., 2005). Outro estudo mostrou que os efeitos do fogo num fragmento de Floresta Estacional Semidecídua em São Paulo, em seis intervalos de tempo diferentes, proporcionaram aumento no número de indivíduos e espécies em cinco dos inventários realizados após o fogo. Os resultados apontaram grande resiliência do fragmento analisado pós-incêndio. No último inventário (66 meses após o fogo), houve redução tanto em espécies quanto em indivíduos, havendo substituição de espécies pioneiras comuns em clareiras (RODRIGUES et al., 2005). Martini et al. (2007) relataram diminuição no número total de espécies das áreas que foram queimadas. Esses resultados corroboram os de Batista e Soares (1997), que indicaram haver diminuição na riqueza de espécies após incêndios intensos, devido aos altos índices de mortalidade.

A rebrota dos indivíduos amostrados foi marcante neste estudo, o que condiz com o papel desse mecanismo de regeneração de espécies arbustivo-arbóreas após a perturbação pelo fogo (KAUFFMAN, 1991; CASTELLANI e STUBBLEBINE, 1993; MARTINS et al., 2002; RODRIGUES et al., 2005). Durante um incêndio florestal, o banco de sementes pode ser drasticamente reduzido pelas altas temperaturas na superfície do solo, 
e dessa forma a rebrota pode passar a ser a principal forma de restauração da vegetação. Os indivíduos que rebrotam após o fogo usam diferentes estratégias, sendo as mais comuns a rebrota da base do tronco queimado, muitas vezes ainda vivo, e a rebrota a partir de raízes enterradas e paralelas ao solo, que lançam brotos em diferentes distâncias do indivíduo remanescente, as chamadas de raízes gemíferas (RODRIGUES et al., 2005; MARTINS e RIBEIRO, 2002). Mesmo assim, Acanthinophyllum ilicifolia e Siparuna bomplandii ocorreram somente após o fogo, provavelmente oriundas do banco de sementes presente no solo.

Confirmando esse padrão de restauração de comunidades arbóreas, Castellani e Stubblebine (1993) observaram 50 espécies com rebrota após o fogo, em que as espécies arbóreas representaram 68,08\% da amostragem total, enquanto no estudo de Martins e Ribeiro (2002) todas as espécies arbóreas rebrotaram após o fogo.

Apesar de o fogo ter queimado todas as plantas amostradas anteriormente e de a rebrota ter tido papel importante na regeneração das espécies no segundo inventário, esperava-se similaridade maior entre as mesmas parcelas antes e depois do fogo, uma vez que se supunha que grande parte dos indivíduos dentro das parcelas apresentasse essa estratégia, porém algumas parcelas tiveram suas florísticas alteradas completamente. A parcela 7 PF teve todas as espécies do inventário antes do fogo queimadas e sem rebrota. Sua composição florística após o fogo foi representada somente por indivíduos de Acanthinophyllum ilicifolia.

Cinco das 10 parcelas foram similares antes e depois do fogo, confirmando a análise de similaridade geral das parcelas antes e depois do fogo.

A baixa representatividade de espécies pioneiras e secundárias tardias nos dois inventários revelou estágio médio de sucessão no estrato da regeneração do fragmento em estudo, o que já havia sido constatado em pesquisa de fitossociologia nesse mesmo trecho de floresta (PAULA et al., 2002).

Em espécies não pioneiras e, portanto, não formadoras de banco de sementes persistentes (GARWOOD, 1989) e sem estratégia de rebrota pósfogo, a chuva de sementes de áreas do entorno do trecho queimado pode ser considerada o principal mecanismo de regeneração neste estudo, como é o caso de Acanthinophyllum ilicifolia, Siparuna guianensis e Dalbegia nigra. Esse fato é confirmado por um estudo sobre chuva de sementes realizado nesse mesmo trecho da floresta, em que $S$. guianensis, $D$. nigra e A. ilicifolia foram as espécies mais representativas (CAMPOS, 2007). Além disso, todas as espécies encontradas nesta pesquisa também apareceram na listagem florística dos estudos de Gasparini Júnior (2004) e Paula et al. (2002) realizados nesse mesmo fragmento, mostrando que existem matrizes que estão sendo responsáveis pela regeneração via chuva de sementes das espécies arbustivo-arbóreas em condições naturais e que após a destruição da vegetação pelo fogo esse mecanismo passa a ser fundamental para aquelas espécies que não rebrotam.

Cochrane e Schulze (1999), analisando os danos causados pelo fogo numa extensa área da Floresta Amazônica, não encontraram padrão claro de seleção de espécies, pois as populações apresentaram taxas de mortalidade semelhantes. As espécies raras estariam mais propensas à extinção local do que as mais abundantes. Mesmo assim, esses autores admitiram a possibilidade de haver espécies particularmente resistentes ao fogo, no caso de florestas sujeitas a incêndios de baixa intensidade.

\section{CONCLUSÃO}

Pode-se concluir que a regeneração florestal pósfogo foi influenciada pela presença de indivíduos adultos remanescentes nas proximidades que funcionaram como fontes de propágulos e pela capacidade de rebrota de algumas espécies. Portanto, o dano causado tende a ser compensado pela resiliência do ecossistema. Contudo, perturbações frequentes por fogo e em maiores escalas podem alterar severamente a composição e estrutura de fragmentos florestais, favorecendo espécies com capacidade de rebrota em detrimento das demais.

\section{REFERÊNCIAS}

ANGIOSPERM PHYLOGENY GROUP - APG II. An update of the Angiosperm Phylogeny Group classification for orders and families of flowering plants: APG II. Botanical Journal of the Linnean Society, v.141, p.399-436, 2003.

BATISTA, A. C.; SOARES, R. V. Manual de preservação e combate a incêndios florestais. Curitiba: Fundação de Pesquisas Florestais, FUPEF, 1997.

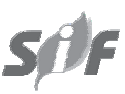

Revista Árvore, Viçosa-MG, v.34, n.6, p.1055 -1063, 2010 
BONFIM, V. R. et al. Diagnóstico do uso do fogo no entorno do Parque Estadual da Serra do Brigadeiro (PESB), MG. Revista Árvore, v.27, n.1, p.87-94, 2003.

BROWN, J. K.; OBERHEU, R. D.; JOHNSTON, C. $M$. Handbook for inventorying surface fuels and biomass in the Interior West. Ogden: Intermountain Forest and Range Experiment Station, 1982. p.1-22. (General Technical Report, INT-129)

CAMPOS, E. P. Fenologia e chuva de sementes em Floresta Estacional Semidecidual no município de Viçosa, Minas Gerais, Brasil. 2007. 50f. Tese (Doutorado em Botânica) - Universidade Federal de Viçosa, Viçosa, MG, 2007.

CASTELLANI, T. T.; STUBBLEBINE, W. H. Sucessão secundária inicial em mata tropical mesófila após perturbação por fogo.

Revista Brasileira de Botânica, v.16, n.2, p.181-203, 1993.

CASTRO, P. S. et al. Interceptação da chuva por mata natural secundária na região de Viçosa MG. Revista Árvore, v.7, n.1, p.76-89, 1983.

CIENTEC. Software Mata Nativa 2: Sistema para Análise Fitossociológica, Elaboração de Inventários e Planos de Manejo de Florestas Nativas. Viçosa, MG: Cientec, 2006.

CLARK, D. A.; CLARK, D. B. Análisis de la regeneración de arboles del dosel em bosque muy húmedo tropical: aspectos teóricos y prácticos. Revista de Biologia Tropical, v.35, n.1, p.41-54, 1987.

COCHRANE, M.; SCHULZE, M. D. Fire as a recurrent event in tropical forest of the eastern Amazon: effects on forest structure, biomass, and species composition. Biotropica, v.31, n.1, p.2-16, 1999.

CONNEL, J. H.; SLATYER, R. O. Mechanisms of succession in natural communities and their role in community stability and organization. The American Naturalist, v.111, n.982, p.1119-1144, 1977.

Revista Árvore, Viçosa-MG, v.34, n.6, p.1055-1063, 2010
CORREA, G. F. Modelo de evolução e mineralogia da fração argila de solos do Planalto de Viçosa, MG. 1984. 87f. Dissertação (Mestrado em Solos e Nutrição de Plantas) Universidade Federal de Viçosa, Viçosa, MG, 1984.

COSTA, C. M. R. et al. Biodiversidade em Minas Gerais: um atlas para a conservação. Belo Horizonte: Fundação Biodiversitas, 1998. 92p.

COUTINHO, L. M. O conceito de cerrado. Revista Brasileira de Botânica, v.1, n.1, p.17-23, 1978.

COUTINHO, L. M. Fire in the ecology of the Brazilian cerrado. In: GOLDAMMER, J. G. (Ed.). Fire in the tropical biota - Ecosystem process and global challenge. Berlim, Springer-Verlag, 1990. p.82-105.

GANDOLFI, S. História natural de uma Floresta Estacional Semidecidual no município de Campinas (São Paulo, Brasil). 2000. 551f. Tese (Doutorado em Biologia Vegetal) - Universidade Estadual de Campinas, Campinas, 2000.

GARWOOD, N. C. Tropical soil seed banks: a review. In: LECK, M.,A.; PARKER, V. T.; SIMPSON, R. L. (Eds.). Ecology of soil seed banks. San Diego: Academic Press, 1989. p.149-209.

GASPARINI JÚNIOR, A. J. Estrutura e dinâmica de um fragmento de floresta estacional semidecidual no campus da Universidade Federal de Viçosa - Viçosa (MG). 2004. 55f. Dissertação (Mestrado em Botânica) - Universidade Federal de Viçosa. Viçosa, MG, 2004.

GERWING, J. J. Degradation of forest through logging and fire in the eastern Brazilian Amazon. Forest Ecology and Management, v.157, n.1/3, p.131-141, 2002.

HOFFMANN, W. A. The effects of fire and cover on seedling establishment in a neotropical savanna.

Journal of Ecology, v.84, n.3, p.383-393, 1996.

KAUFFMAN, J. B. Survival by sprouting following fire in tropical forest of the Eastern Amazon. Biotropica, v.23, n.3, p.219-224, 1991. 
McARTHUR, A. G; CHENEY, N. P. The characterization of fire in relation to ecological studies. Australian Forest Research, v.2, n.1, p.36-45, 1966.

MAGURRAN, A. E. Diversidad ecológica y su medición. Madri: Ediciones Vedrà, 1989.

MARTINI, A. M. Z. et al. Community structure of vascular plants in treefall gaps and fire-disturbed habitats in the Atlantic rainforest, southern Bahia, Brazil. Revista Brasileira de Botânica, v.30, n.2, p.303-313, 2007.

MARTINS, S. V.; RIBEIRO, G. A. Initial secondary succession in a Forest fragment disturbed by fire in Viçosa - MG. In: VIEGAS, D. X. (Ed.) forest fire research and wildland fire safety. Rotterdam: Millpress, 2002. p.1-9.

MARTINS, S. V.; RODRIGUES, R. R. Gap-phase regeneration in a semideciduous mesophytic forest, south-eastern Brazil. Plant Ecology, v.163, n.1, p.51-62, 2002.

MARTINS, S. V. et al. Regeneração pós-fogo em um fragmento de Floresta Estacional Semidecidual no município de Viçosa, MG. Ciência

Florestal, v.12, n.1, p.11-19, 2002.

MUELLER-DOMBOIS, D.; ELLENBERG, H. Aims and methods of vegetation ecology. New York: John Wiley \& Sons, 1974. 547p.

PAULA, A. et al. Alterações florísticas ocorridas num período de quatorze anos na vegetação arbórea de uma floresta estacional semidecidual em Viçosa MG. Revista Árvore, v.26, n.6, p.743-749, 2002.
PIELOU, E. C. Ecological diversity. New York, John Wiley \& Sons, 1975.

RODRIGUES, R. R.; MARTINS, S. V.; MATTHES, L. H. F. Post-fire regeneration in a semideciduous mesophytic forest, south-easthern Brazil. In: BURK, A. R. (Ed.) New research on forest ecosystems. New York: Nova Science Publishers, 2005. p.1-19.

SILVA, V. F. et al. Impacto do fogo no componente arbóreo de uma floresta estacional semidecídua no município de Ibituruna, MG, Brasil. Acta

Botânica Brasílica, v.19, n.4, p.701-716, 2005.

TABARELLI, M.; VILLANI, J. P.; MANTOVANI, W. Estudo comparativo da vegetação de dois trechos de floresta secundária no Núcleo Santa Virginia, Parque Estadual da Serra do Mar, SP. Revista do Instituto Florestal, v.6, n.1, p.1-11, 1994.

UHL, C.; CLARK, K.; CLARK, H.; MURPHY, P. Early plant succession after cutting and burning in the upper Rio Negro region of the Amazonian basin. Journal of Ecology, v.69, n.2, p.631-649, 1981.

VELOSO, H. P.; HANGEL-FILHO, A. L. R.; LIMA, J. C. Classificação da vegetação brasileira, adaptada a um sistema universal. Rio de Janeiro: IBGE, 1991. 124p.

WADE, D. D.; LUNDSFORD, J. Fire as a management tool: prescribed burning in the Southerm United States. Unasylva, v.41, n.162, p.28-38, 1990. 